\title{
Heart and head
}

Cite as: CMAJ 2019 February 4;191:E136-7. doi: 10.1503/cmaj.180907

CMAJ Podcasts: audio reading at https://soundcloud.com/cmajpodcasts/180907-enc

was driving to pronounce somebody dead. The person's name had startled me.

"You're on call for Dr. C. tonight, right?" The answering-service operator had been businesslike. "One of his patients just died at home. Her friend phoned. They need a doctor to pronounce her. The name is Madeline M."

Could it be my Miss M.? For years I had been imagining finding her to thank her for the impact she had on me. Contacting her was on that long list of things to do one day, when I had more time. But there were always higher priorities. I was busy single-parenting my 3 children on alternate weeks, trying to keep them happy and fed, ferrying them to school and activities. I was also tending to a full-time medical practice, seeing my office patients, doing hospital rounds and delivering babies at all hours. Eventually, I thought, I would get around to that to-do list.

Someday. Yes, when life calmed down.

But somehow it never did.

I drove up to a small house in an older part of the city, crowded cozily between its neighbours. A gaunt woman answered the door and introduced herself as Miss M.'s good friend. She showed me into a downstairs bedroom. I thanked her; saw her hands and lips trembling. She gave my arm a little squeeze and quickly left. On the bed lay Miss M., still and peaceful. It had been 22 years since I had sat in her classroom. Her once-animated face was slack now, yet there was no mistaking her thin features, wispy hair, long fingers. It was strangely comforting to see her again.

Miss M. had been older than our other teachers, tall and slim in her long skirts and long-sleeved blouses. Her bony face and bright eyes were set below silver, straight hair. There was a plainness and tidiness about her but, also, just beneath the

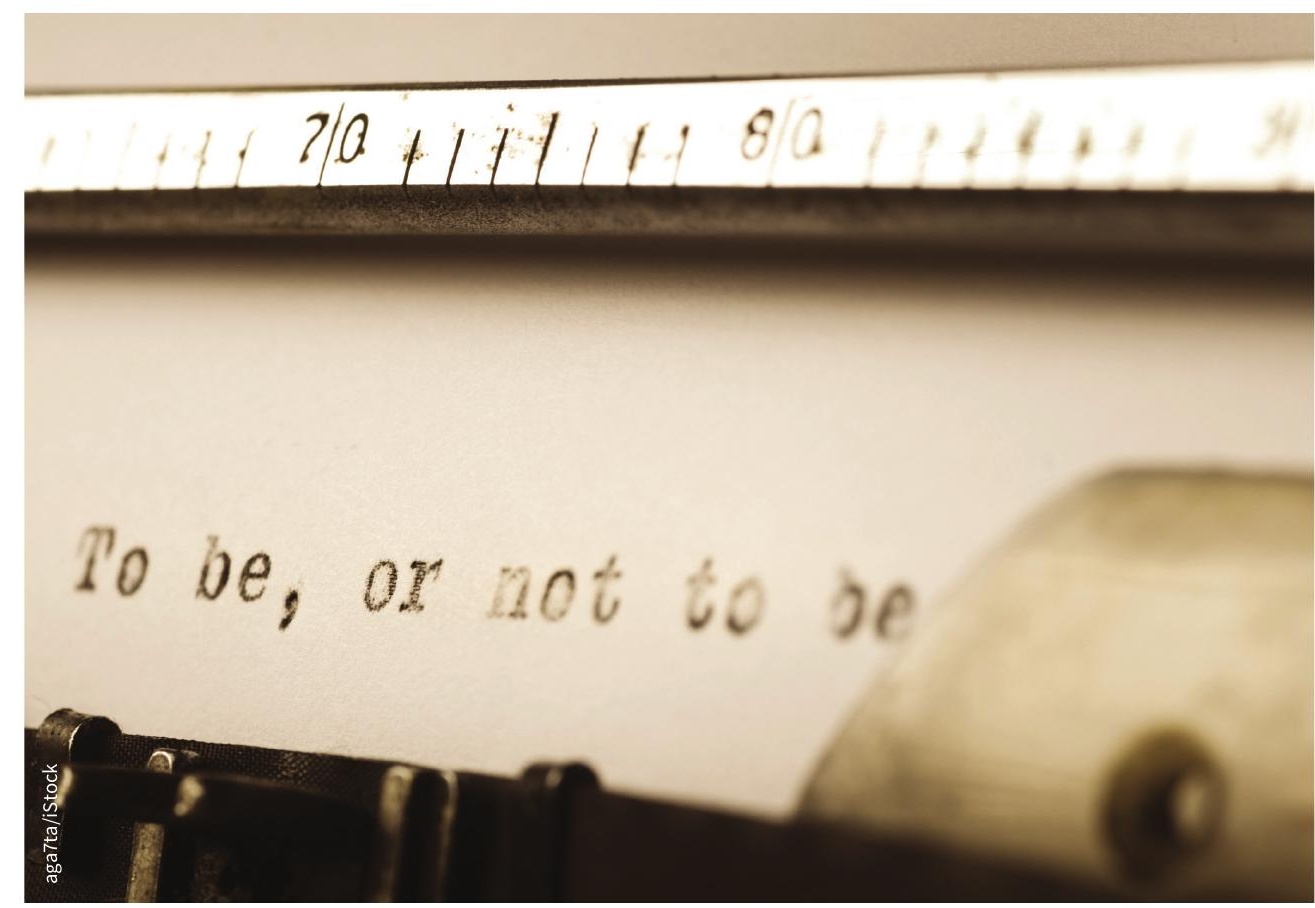

surface, an intensity. In my memory she is always leaning forward, actively listening.

In her classroom - I sat near the front - exciting thoughts were let loose. Reason versus emotion, anger and conflict, love and longing. Miss M. discussed ideas that mattered. "The core of most literature," she would tell us, "comes down to the fundamental conflict between the human heart and the head."

I leaned forward. This resonated. My adolescent mind was trying to understand the world rationally and intellectually, but I was also swimming with feelings, buffeted by hormones. In the literature that Miss M. taught, I could see my own clashes of head and heart illuminated through the struggles of the characters. I saw my tumult of strong emotions - anger at social injustice, infatuation with a high-school girlfriend - reflected in the books we studied.
As she read and explained Macbeth to us, I clung to her words. "Let not light see my black and deep desires," she quoted. "Life is a tale told by an idiot, full of sound and fury, signifying nothing." She put down her book, looked straight at me: "Peter, what do you think about that?"

I was not sure.

I was in the midst of trying to reconcile these competing impulses within myself. It was my last year of high school and university was approaching, but my choices of study seemed starkly contrasting.

On one hand, Miss M. inspired me to become an English teacher myself.

What a great job, I thought, introducing keen students to big ideas through literature. I could spend my life doing this!

But I also loved my biology courses, and chemistry and physics. Even math. I hated the thought of giving up any of 
them. Yet the worlds of science and of the humanities seemed like 2 solitudes, isolated from each other. Where did I belong? How could I split myself?

Medicine, I eventually decided, could be the bridge between the worlds I loved: science and the humanities, head and heart. Medicine would keep me whole.

In the premedical years, I loved the immersion into science - the labs, the logic of the learning - no less than the courses in English literature and philosophy. In the summer after the first intense year of medical school, I scrubbed my hands for days to remove the stink of formaldehyde from the anatomy lab where we dissected human cadavers, then escaped to a distant university to take an English literature course. The next year, I skipped some physiology classes to read Othello. But in the immersion into love and betrayal, ambition and despair, a part of me held back: the would-be scientist, observing. How do humans actually negotiate our contradictory, internal impulses, I wondered. What would science make of this? If thoughts and feelings are products of the physical brain, how does all this really happen?

How can the same brain editorialize on its own emotional responses?

Later, when it came time to pick a specialty, I chose comprehensive family medicine. There, I hoped, I might best use all sides of myself, and work with the whole person: physical, psychological and social issues, together.

When I entered practice, no problems seemed to be either purely physical or entirely psychological. Like all new doctors, I learned how things that seemed to be wholly physical were strongly affected by patients' emotional states. Very anxious people experienced more pain with fractures. Asthma was worsened by stress. As were angina, eczema; it seemed almost everything. On the other hand, problems that at first glance appeared purely emotional were often caused by physical diseases. I marveled how some people who reported excessive anxiety felt fine after their hyperthyroidism was diagnosed and treated. Other patients had depression caused by organic disease. Shortly after graduation I saw E., a man of 60 with profound depression. I was puzzled when he did not improve with normal therapies, until investigation showed the presence of hypercalcemia. Once the underlying hyperparathyroidism was treated, E.'s depression melted away; his energy returned, and he regained his sense of purpose in life. How many famous characters in history and literature, I wondered, might have turned out differently if they had had access to modern diagnosis?

Body and mind, intertwined in a dance of constant interaction.

It is satisfying, trying to balance these realms. Attempting to systematically, rationally problem solve while staying connected with the patient's emotional complexity - those fractures one cannot x-ray or easily measure. Feeling within myself the reconciliation of science and humanities, Miss M.'s "head and heart."

I had always wanted to tell Miss M. that I am the doctor I am partly because of Othello and Macbeth, and the images from literature that she illuminated. That she helped me at an impressionable age to realize the power of emotions to affect physical and mental health. That she and her questions helped me later in my search for integration. And that, as I had hoped, I found mind and body to be inseparable in medicine. The worlds of science and art are indeed joined, and I am not split.

Miss M. lies still, waiting. In some ways I have moved far from her world, but, ironically, it is that very decision - to become a doctor - that has brought me back to her.
I look at her closed eyes, the stilled face. On the bookshelf behind her bed is a row of books - political volumes, novels, plays - written by a generation of her former students. I recognize some of their names from high school. As I scan the titles, I imagine her enormous pride. She was childless; my heart quickens to realize those students had been her children.

I sit down on the side of her bed, ready to follow protocol. But it feels awkward sliding my stethoscope under her nightgown and onto her bare chest. I hesitate, catch my breath at the violation. I have a sudden vision of myself as a 17-year-old in her classroom, and what I am now doing gives me a flash of sadness and confusion.

The moment passes, and professionalism takes over. I am again the methodical physician. I know the drill: I note the skin discolouration. I check her pupils; they are fixed and dilated. I listen for heart sounds; there are none.

I put away my stethoscope and take her hand. It is still a little warm and not yet stiff. I lean towards her. The room is silent. I wish I had contacted her long ago, not put it off. All those things we tell ourselves we will get around to one day when there is time.

An image comes, her eyes bright in the classroom.

"For years I've been meaning to find you and tell you how you inspired me. And to think, I almost missed the chance."

\section{Peter R. Newman MD}

Department of Family and Community Medicine, University of Toronto, Toronto, Ont.

This article has been peer reviewed.

This is a true story, although it happened long ago. Pertinent details have been changed to ensure anonymity. 